\title{
Nanomicelles potentiate histone deacetylase inhibitor efficacy in vitro
}

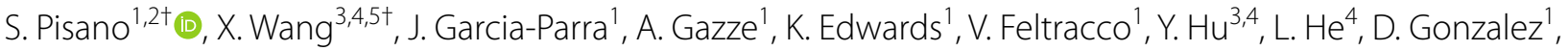 \\ L. W. Francis ${ }^{1}$, R. S. Conlan ${ }^{1}$ and C. Li ${ }^{4^{*}}$
}

${ }^{*}$ Correspondence: cli12@xjtu.edu.cn

†S. Pisano and X. Wang have contributed equally to the work

${ }^{4}$ Xi'an Jiaotong University Suzhou Academy,

Suzhou 215123, People's

Republic of China

Full list of author information is available at the end of the article

\begin{abstract}
Background: Amphiphilic block copolymers used as nanomicelle drug carriers can effectively overcome poor drug solubility and specificity issues. Hence, these platforms have a broad applicability in cancer treatment. In this study, Pluronic F127 was used to fabricate nanomicelles containing the histone deacetylase inhibitor SAHA, which has an epigenetic-driven anti-cancer effect in several tumor types. SAHA-loaded nanomicelles were prepared using a thin-film drying method and characterized for size, surface charge, drug content, and drug release properties. Loaded particles were tested for in vitro activity and their effect on cell cycle and markers of cancer progression.

Results: Following detailed particle characterization, cell proliferation experiments demonstrated that SAHA-loaded nanomicelles more effectively inhibited the growth of HeLa and MCF-7 cell lines compared with free drug formulations. The $30 \mathrm{~nm}$ SAHA containing nanoparticles were able to release up to $100 \%$ of the encapsulated drug over a $72 \mathrm{~h}$ time window. Moreover, gene and protein expression analyses suggested that their cytoreductive effect was achieved through the regulation of p21 and p53 expression. SAHA was also shown to up-regulate E-cadherin expression, potentially influencing tumor migration.
\end{abstract}

Conclusions: This study highlights the opportunity to exploit pluronic-based nanomicelles for the delivery of compounds that regulate epigenetic processes, thus inhibiting cancer development and progression.

Keywords: Pluronic, Drug delivery, Nanomicelles, Epigenetic drugs, Cancer, SAHA

\section{Background}

Chemical compounds directly targeting epigenetic processes have emerged as potential treatments for metastatic disease (Fardi et al. 2018). Epigenetics involves alterations to the DNA and chromatin landscape and consequently gene expression patterns and biological processes (Dupont et al. 2009). The molecular alterations to the nucleosomeforming histone proteins are one of the major epigenetic modifications that have been found to be altered in cancer (Audia and Campbell 2016). Compounds targeting these modifications, reverting them to a non-cancer state, have great therapeutic potential. Suberoylanilide Hydroxamic Acid (SAHA, commercially known as Vorinostat) 
is approved by the FDA for the treatment of malignant cutaneous T-cell lymphoma (CTCL) (Kawamata et al. 2007). Subsequently, it was found to offer therapeutic potential for other cancer types including cervical and breast (Prestegui-Martel et al. 2016; Shi et al. 2017) where female breast cancer represents around $30 \%$ of all new cancer cases in the US yearly, while uterine and cervical cancer make up to $7 \%$ of the total (Siegel et al. 2020). The use of MCF-7 and HeLa for breast and cervical cancer studies involving epigenetic drugs is well established due to the high genetic variability of these cells lines that could be tackled by such an approach (Landry et al. 2013; Zhou et al. 2019).

SAHA is a histone deacetylase (HDAC) inhibitor that can mediate the down-regulation of DNA transcription in numerous biological processes (Haberland et al. 2009) including cell growth arrest, activation of the extrinsic and intrinsic apoptotic pathways, autophagic, reactive oxygen species (ROS)-induced cell death, and mitotic cell death (Xu et al. 2007; Ververis et al. 2013; Zhang and Zhong 2014). Limitations in SAHA utility include low bioavailability, short half-life, and toxic side-effects, which are partly linked to the development of multidrug resistance (Bravo-Cordero et al. 2012; Friedl et al. 2012; Chung et al. 2013). Together, these factors have limited the clinical use of SAHA as an effective anti-cancer treatment (Konsoula and Jung 2008; Qi et al. 2017). Encapsulating SAHA within nanoparticles represents a potential strategy for overcoming such limitations to enhance its utility in clinic.

Nanoparticles including liposomes (Lee 2020), bio-nanocapsules (Tsutsui et al. 2007), and polymeric nanoparticles (El-Say and El-Sawy 2017) are being developed to overcome poor solubility and drug efficacy (Zhu and Liao 2015). Due to the unique physiological and pathological features of the tumor site, correctly sized nanomicelles can be passively targeted due to the enhanced permeability and retention (EPR) effect, which can improve the drug efficacy and reduce toxic side-effects (Fang et al. 2011; Zhu et al. 2016; Russo et al. 2016). Nanomicelles possess unique advantages including structural stability and simplicity of fabrication in a 10-100 nm size range (Tran et al. 2014; Kwak et al. 2015). They can also effectively prolong the retention time of drugs in vivo and prevent drug inactivation by enzyme degradation before reaching the tumor site (Biswas et al. 2013).

Pluronic is a water-soluble amphiphilic molecule with a poly(oxyethylene)-block-poly (oxypropylene)-block-poly(oxyethylene) (PEOx-PPOy-PEOz) triblock structure (Farrugia et al. 2014), which self-assembles forming core-shell micelles in aqueous media. For instance, chlorpromazine (CPZ)-containing Pluronic nanomicelles have been shown to enhance the cytotoxicity of the drug and increase its selectivity towards chronic myeloid leukemia cells, demonstrating the pharmacological potential for cancer treatment (Mello et al. 2016). Moreover, Solasodine, a type of steroidal alkaloid that exhibits excellent bioactivities against fungi, viruses, and especially tumors, has been encapsulated into Pluronic F127 nanocarriers, and was able to enhance the anti-cancer effect of Solasodine alone in A549 and Hela cells (Zhang et al. 2015). A similar approach has also been used for doxorubicin hydrochloride-loaded pluronic F127 nanocapsules which demonstrated delayed drug release (Zeng et al. 2014).

Here, we showed that the HDAC inhibitor SAHA can be efficiently loaded into pluronic F127 nanomicelles. We demonstrate that SAHA-loaded nanomicelles are able to efficiently release the drug in a time-dependent fashion. SAHA nanomicelles were shown 
to be more efficient than the free drug in reducing cell viability and inhibiting cell migration capacities of breast and cervical cancer cell lines, which represent two cancer types that still require more effective, epigenetic-based, treatments. Cellular uptake studies demonstrated the effective micellular uptake and intracellular distribution in a cell linedependent fashion. In addition, the encapsulated SAHA remained effective in triggering cell cycle arrest and apoptosis in a dosage-dependent manner. The HDAC inhibitor also altered the expression of the EMT markers E-cadherin and N-cadherin, suggesting that effective delivery has the potential to reverse the aggressive, metastatic phenotype of these cancer models.

\section{Methods}

\section{Chemicals and reagents}

Pluronic F127 was purchased from Sigma, China. SAHA was purchased from Nanjing Duolun Chemical Co., Ltd., China. Propidium Iodide (PI) was purchased from Santa Cruz Biotechnology. Acetonitrile, Dimethyl Sulfoxide (DMSO), Ammonium Persulfate, Sodium Chloride, Dodecyl Sodium Sulfate, Tween 20, Methanol, Ethanol, Isopropanol, and Chloroform were purchased from Sinopharm Chemical Reagent Co., Ltd., China. Phosphate-Buffered Saline, Dulbecco's Modified Eagle Medium (DMEM), 1640 Medium, Trypsin were purchased from Solarbio. Fetal Bovine Serum was purchased from Corning. MTT, Glycine, Tris(hydroxymethyl)aminomethane, and Acrylamide were purchased from Aladdin, China.

\section{Preparation of SAHA-pluronic F127 nanoparticles}

$200 \mathrm{mg}$ of Pluronic F127 and $3 \mathrm{mg}$ of SAHA were dissolved into $10 \mathrm{ml}$ of acetonitrile. Subsequently, the solvent was removed by rotary evaporation at $55^{\circ} \mathrm{C}$ with decompression. The solid copolymer matrix obtained was then preheated at $65^{\circ} \mathrm{C}$ for $1 \mathrm{~h}$ and eventually hydrated with phosphate buffer solution (PBS, $10 \mathrm{mM}$ or $150 \mathrm{mM} \mathrm{NaCl}$ ) or $\mathrm{H}_{2} \mathrm{O}$. The nanomicellar solution was filtered with a $0.22 \mu \mathrm{m}$ filter to remove any free drug. PI encapsulation was similarly achieved. $10 \mathrm{mg}$ PI and $200 \mathrm{mg}$ were dissolved in $10 \mathrm{ml}$ of acetonitrile, and followed the same process explained above. The dispersion, size, and zeta potential of nanomicelles were measured by dynamic light scattering (Particle size analyzer, Malvern, UK).

\section{Atomic force microscope (AFM) characterization}

$10 \mu \mathrm{L}$ of nanomicelle aliquots were spotted on mica substrates at a concentration of $100 \mu \mathrm{g} / \mathrm{mL}$ (Agar Scientific, UK) and dried at room temperature. Sample topography was obtained in air using a Bruker BioScope Catalyst (Bruker Instruments, Santa Barbara, California, USA) AFM. Bruker ScanAsyst-Air cantilevers were used, with a nominal spring constant of $0.4 \mathrm{~N} / \mathrm{m}$ and a nominal resonant frequency of $70 \mathrm{kHz}$. All imaging was conducted using Peak Force Tapping (PFT) in ScanAsyst Mode. Images were processed with first-order flattening and planefit using Bruker Nanoscope Analysis 1.5. Gwyddion in-built grain analysis was used to identify nanomicelles and to calculate their size. 


\section{Nanomicelle stability}

Nanoparticles were resuspended in either $\mathrm{H}_{2} \mathrm{O}$, PBS $(10 \mathrm{mM} \mathrm{NaCl})$, or PBS $(150 \mathrm{mM}$ $\mathrm{NaCl})$, and stored at $4^{\circ} \mathrm{C}$. To assess the stability of each formulation over time, size and poly-dispersion (PDI) measurements were taken at $0,5,10,15,20,25$, and 30 days.

\section{Drug release assessment}

A high-performance liquid chromatography (HPLC) system (Waters 2535, Milford, MA, US) equipped with a photodiode array detector was used for the analysis of the drug release potential of the pluronic formulations. A C18 HPLC column (GraceSmart RP C18, $4.6 \mathrm{~mm} \times 250 \mathrm{~mm}, 5 \mu \mathrm{m}$ ) was used for quantitative analysis of SAHA. Mobile phase A contained HPLC grade $\mathrm{H}_{2} \mathrm{O}$, and mobile phase $\mathrm{B}$ contained HPLC grade acetonitrile. SAHA was eluted with $50 \%$ mobile phase A and mobile phase B at a flow rate of $1 \mathrm{ml} / \mathrm{min}$, with a retention time of $3.6 \mathrm{~min}$ and UV detection at $265 \mathrm{~nm}$. Standard curves of concentration peaks and areas were drawn. Five-point calibration curves for SAHA in the range of 31.25-500 $\mu \mathrm{M}$ were considered reliable $\left(r^{2} \geq 0.999\right)$.

\section{Determination of drug loading and entrapment efficiency.}

$200 \mu \mathrm{l}$ of nanomicelle solution were added with $800 \mu \mathrm{l}$ acetonitrile and centrifuged for $5 \mathrm{~min}$ at $10,225 \times g$. The supernatant was used to determine the concentration of drug by HPLC.

The entrapment efficiency (EE) and drug loading efficiency (DL) were calculated as follows:

$$
\begin{aligned}
& \mathrm{DL} \%=\frac{\text { Weight of drug in nanomicelles }}{\text { Weight of drug loaded nanomicelles }} * 100 \% \\
& \mathrm{EE} \%=\frac{\text { Weight of drug in nanomicelles }}{\text { Weight of drug added into nanomicelles }} * 100 \% .
\end{aligned}
$$

\section{In vitro drug release}

To measure the release of SAHA from nanomicelles, a $20 \mathrm{ml}$ solution containing SAHA-loaded nanomicelles was loaded into a dialysis bag (MWCO: $8000 \sim 14,000 \mathrm{Da}$, Spectrum $^{\circledR}$, Rancho Dominquez, CA, USA), which was immersed in $500 \mathrm{ml}$ of $10 \mathrm{mM}$ PBS ( $\mathrm{pH}$ 7.4). Temperature was maintained at $37^{\circ} \mathrm{C}$. At predetermined time intervals, $1 \mathrm{~mL}$ of release medium (PBS) was withdrawn and replaced with the same volume of fresh PBS into the system. The concentration of SAHA inside the solution was determined by HPLC.

\section{Cell lines}

HeLa (human epithelial cervical cancer) and MCF-7 (human breast adenocarcinoma) cell lines were kindly donated by Suzhou Institute of Nano-Tech and Nano-Bionics (SINANO), Chinese Academy of Sciences. HeLa cells were grown in DMEM and MCF-7 cells in RMPI. All media was supplemented with penicillin $(100 \mathrm{U} / \mathrm{ml})$ and 
streptomycin $(100 \mu \mathrm{g} / \mathrm{ml})$ and $10 \% \mathrm{FBS}$ at $37^{\circ} \mathrm{C}$ in a humidified $5 \% \mathrm{CO}_{2}$ and $95 \%$ air atmosphere.

\section{Cell proliferation assay}

The anti-proliferative effects of SAHA, SAHA-loaded nanomicelles, and empty nanomicelles were assessed using the 3-(4,5-dimethyl-2-thiazolyl)-2,5-diphenyl-2-Htetrazolium bromide (MTT) assay (Aladdin, China). $1 \times 10^{4}$ cells/well were seeded in 96-well plates, grown overnight, and then treated with various concentrations of SAHA, SAHA-loaded nanomicelles, and empty nanomicelles for $24 \mathrm{~h}, 48 \mathrm{~h}$, or $72 \mathrm{~h}$. $20 \mu \mathrm{L}$ of MTT reagent were added to each well and left incubating for $4 \mathrm{~h}$. The optical density was determined at $490 \mathrm{~nm}$ using a Multifunctional Microplate Reader (Thermo Fisher, China).

\section{Protein blot}

$2.5 \times 10^{5}$ cells were dispersed in three 6-well plates, grown overnight, and three plates treated with SAHA, SAHA nanomicelles and empty nanomicelles for $24 \mathrm{~h}$ or $48 \mathrm{~h}$. The cells were lysed in RIPA lysis buffer containing protease and phosphatase inhibitors (Beyotime, China) and total protein was estimated with BCA Protein Assay Kit (Beyotime, China). Protein was separated by SDS-PAGE and transferred on PVDF membranes (Beyotime, China). The membranes were blocked in 5\% skimmed milk, incubated with primary antibodies for p21, p53, N-Cadherin or E-cadherin (Santac Cruz, US), and then incubated with the appropriate HRP conjugated secondary antibody (Absin, China).

\section{Quantitative RT-PCR (qRT-PCR)}

Hela and MCF-7 cells were treated with the SAHA and SAHA-loaded nanomicelles for $24 \mathrm{~h}$ or $48 \mathrm{~h}$. Total RNA was isolated using the RNAiso Plus kit (Takara, Japan). 10 $\mu \mathrm{g}$ of total RNA was converted into complementary DNA (cDNA) with PrimeScript RT reagent kit with gDNA Eraser (Takara, Japan). SYBR Premix Ex TaqTMII (Takara, Japan) solution was used according to the manufacturer's protocol to measure for mRNA expression of p53, p21, E-cadherin and N-cadherin with by qPCR. GAPDH was used as a control to determine relative mRNA expression. The table below shows the primer sequences used.

\begin{tabular}{lll}
\hline Gene & & Primer sequence \\
\hline GAPDH & Forward primer & $5^{\prime}$-GCACCGTCAAGGCTGAGAAC-3' \\
& Reverse primer & $5^{\prime}$-TGGTGAAGACGCCAGTGGA-3' \\
p21 & Forward primer & $5^{\prime}$-GATGGAACTTCGACTTTGTCACC-3' \\
& Reverse primer & $5^{\prime}$-CTGCCTCCTCCCAACTCATC-3' \\
p53 & Forward primer & $5^{\prime}$-ACTCCCCTGCCCTCAACAA-3' \\
& Reverse primer & $5^{\prime}$-ATCCAAATACTCCACACGCAAA-3' \\
E-cadherin & Forward primer & $5^{\prime}$-AGGATGACACCCGGGACAAC-3' \\
& Reverse primer & $5^{\prime}$-TGCAGCTGGCTCAAGTCAAAG-3' \\
N-cadherin & Forward primer & $5^{\prime}$-CGAATGGATGAAAGACCCATCC-3' \\
& Reverse primer & $5^{\prime}$-GCCACTGCCTTCATAGTCAAACACT-3' \\
\hline
\end{tabular}




\section{Cellular uptake of nanomicelles}

$1.5 \times 10^{4} \mathrm{HeLa}$ and MCF-7 cells/well were seeded in 8-well chambered coverslips (Ibidi). After $24 \mathrm{~h}$ from seeding, cells were treated with $1 \mu \mathrm{M}$ of PI-loaded pluronic F127 nanoparticles and incubated at $37{ }^{\circ} \mathrm{C}$ in a humidified atmosphere. PBS was added as the untreated control. After $4 \mathrm{~h}, 24 \mathrm{~h}$, and $48 \mathrm{~h}$, cells were washed with 1X PBS and nuclei were counterstained with Hoechst 33342 (Life Technologies). 0.1\% Triton-X-100 was used as a positive control and added to cells for $10 \mathrm{~min}$ to permeabilize them, followed by $1 \mu \mathrm{M}$ PI treatment for $10 \mathrm{~min}$. Cells were imaged live on a Zeiss LSM710 fluorescent confocal microscope (Carl Zeiss Microscopy, Jena) at a 40X magnification using the $543 \mathrm{~nm}$ and $405 \mathrm{~nm}$ laser lines.

\section{Cell migration assay}

MCF7 and HeLa cells were seeded at a $5 \times 10^{5}$ cells/well concentration in 6-well plates. When cells reached $90 \%$ confluence scratches were performed with a $200 \mu \mathrm{l}$ sterile pipette tip and detached cells were washed in $1 \times$ PBS. Subsequently, empty nanomicelles, SAHA nanomicelles, and free SAHA were added to each well, and the final volume was brought to $2 \mathrm{ml}$ with FBS-free media. Images were acquired at $0 \mathrm{~h}, 24 \mathrm{~h}$, and $48 \mathrm{~h}$ using a Zeiss inverted microscope at a $4 \times$ magnification.

Reference marks on the bottom of each well along the scratches were made to align the same fields in each image acquisition, at each time point. Image analysis of the scratches was performed using the Wound Healing Size Tool, an ImageJ/Fiji ${ }^{\circledR}$ plugin that allows for the quantification of the wounded area (Suarez-Arnedo et al. 2020). The scratch area was calculated for each field and time point, and the percentage of wound closure was calculated according to the following formula:

$$
\text { Wound closure } \%=\left(\frac{A_{t=0}-A_{t=\Delta t}}{A_{t=0}}\right) * 100 \text {, }
$$

where $A_{t=0}$ is the area of a specific field at time $0 \mathrm{~h}$ and $A_{t=\Delta t}$ is the area of the same field after $n$ hours of the initial scratch. The data were graphed and analyzed using GraphPad Prism. For the statistical analysis, it was used one-way ANOVA with Dunnett's multiple comparison test.

\section{Statistical analysis}

Data were expressed as mean \pm standard deviation and analyzed using SPSS software. According to the distribution type of the data, the samples were processed by $T$ test and one-way ANOVA analysis with Dunnett's multiple comparison test. A $p$ value $p<0.05$ was considered statistically significant.

\section{Results}

\section{Characterization and assessment of stability of SAHA-loaded nanomicelles over time}

Nanomicelles were fabricated using a thin-film method and characterized by dynamic light scattering. Empty and SAHA-loaded nanomicelles both had an average size of $23 \mathrm{~nm}$ and a poly-dispersive index (PDI) of $0.09 \pm 0.02$ and $0.08 \pm 0.0$, respectively, confirming the uniformity of distribution of the formulation (Table 1). The surface charge of the particles was measured with a Zetasizer Nano instrument (Malvern, UK), providing 
Table 1 Characterization of SAHA-encapsulated pluronic nanomicelles

\begin{tabular}{llllll}
\hline & Size & PDI & Zeta potential & EE\% & DL\% \\
\hline $\begin{array}{l}\text { SAHA-loaded pluronic F127 } \\
\text { nanomicelles }\end{array}$ & $22.98 \pm 1.01$ & $0.08 \pm 0.01$ & $-1.28 \pm 0.28$ & $94.36 \pm 0.76$ & $1.31 \pm 0.06$ \\
Pluronic F127 nanomicelles & $22.56 \pm 0.3$ & $0.09 \pm 0.02$ & & & \\
\hline
\end{tabular}

Size, PDI, and surface charge were analyzed using Malvern's Zetasizer Nano. Entrapment efficiency and drug loading efficiency were calculated as explained in Sect. 2.2
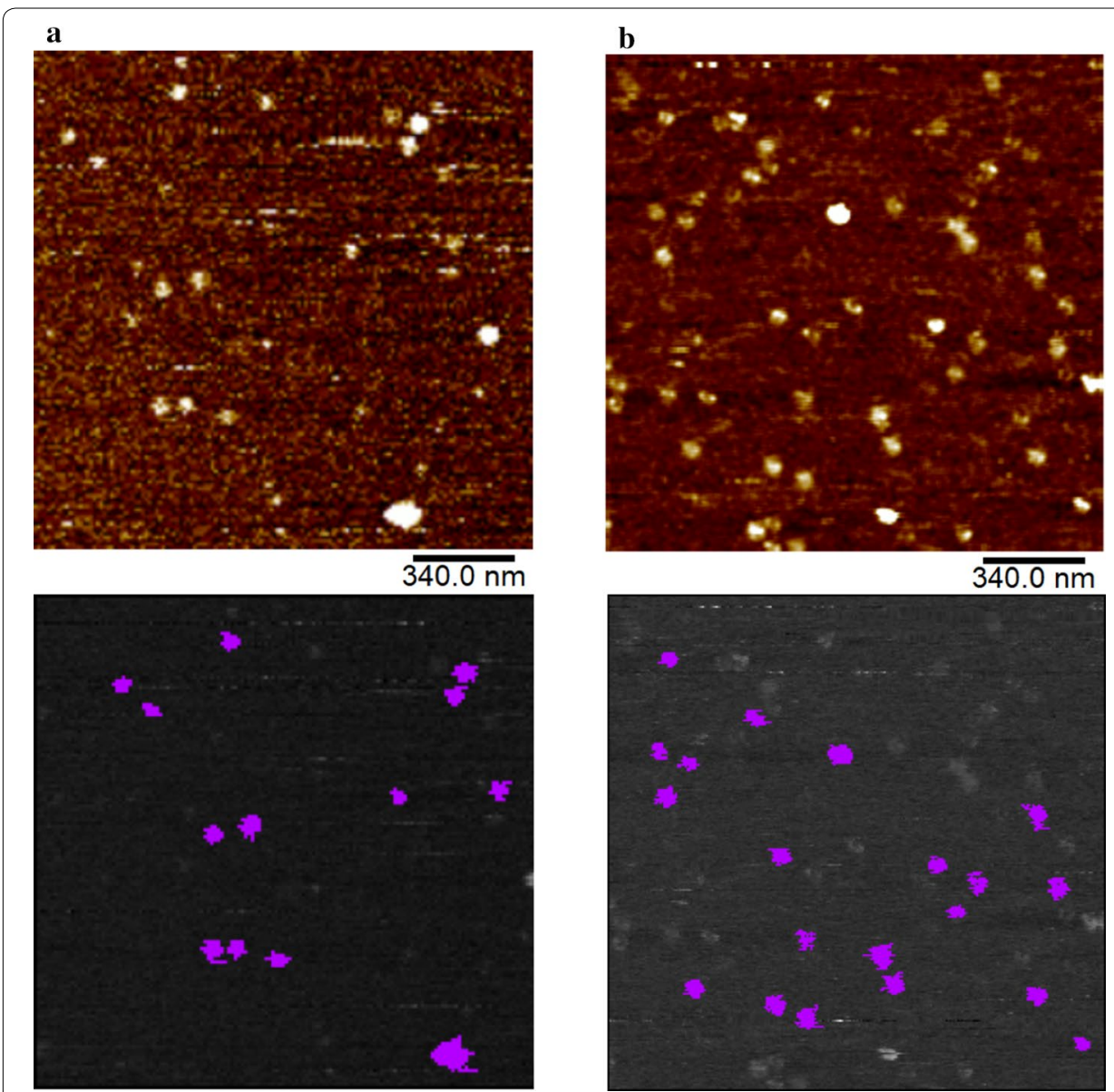

Fig. 1 AFM characterization. Empty nanomicelles and SAHA-loaded nanomicelles are shown at the top of $\mathbf{a}$ and $\mathbf{b}$, respectively. $Z$ range: $0-1.8 \mathrm{~nm}$. Gwyddion grain analysis was used to identify nanomicelles (bottom images, masking is highlighted in purple) and to calculate their diameter. Not all nanomicelles were considered for grain analysis due to low masking performance

a zeta-potential value of $-1.28 \pm 0.28 \mathrm{mV}$. The entrapment efficiency (EE\%) and drug loading efficiency (DL\%) values were $94.36 \pm 0.76 \%$ and $1.31 \pm 0.062 \%$, respectively.

Particles were imaged using Atomic Force Microscope (AFM) and identified using the grain analysis algorithm in Gwyddion (Kohn et al. 2018). Nanomicelles showed a rounded shape and both empty (Fig. 1a) and SAHA-loaded (Fig. 1b) nanomicelles presented a diameter of $32 \mathrm{~nm}$. Both AFM and DLS experiments confirmed that no change was detectable in micelles dimensions upon incorporation of the drug. 

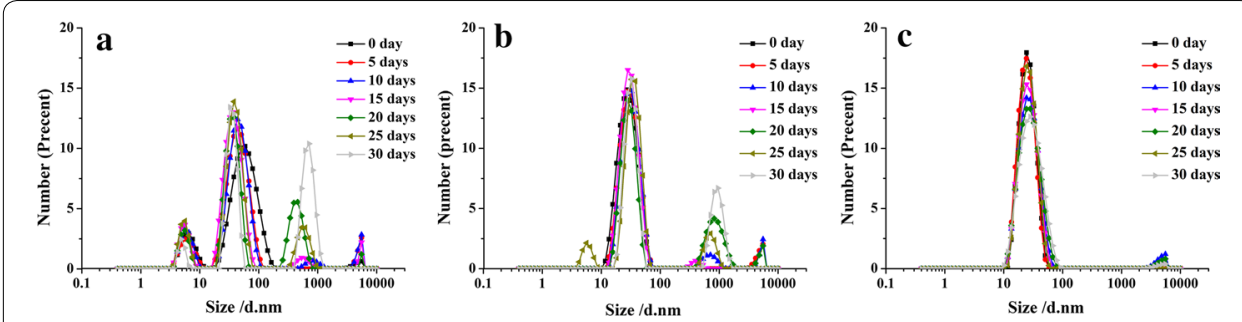

Fig. 2 Analysis of nanoparticles stability over time. The aggregation of nanomicelles in three different solvents was investigated at $0,5,10,15,20,25$, and 30 days. Nanoparticles were kept at $4^{\circ} \mathrm{C} .1 \mathbf{a} \mathrm{H}_{2} \mathrm{O} ; \mathbf{1} \mathbf{b}$ 10 mM PBS; 1c 150 mM PBS

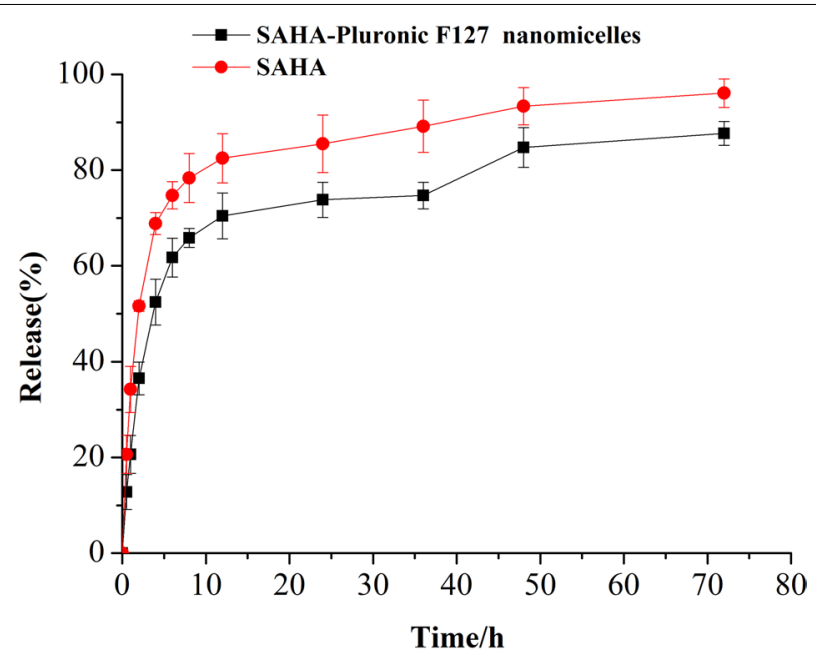

Fig. 3 In vitro drug release of SAHA from nanomicelles. Nanomicelles encapsulated with SAHA and resuspended in PBS were tested for their capacity to release the drug over time. HPLC was used to measure the amount of SAHA released after up to $72 \mathrm{~h}$. The \pm SD value of the data was tested by $T$ test $(n=3)$

To determine nanomicelle stability, particle size was evaluated in three different solutions $\left(\mathrm{H}_{2} \mathrm{O}, 10 \mathrm{mM}\right.$ PBS and $150 \mathrm{mM}$ PBS $)$ at different time points for up to 30 days (Fig. 2). In all three solutions, the initial particle size of SAHA nanomicelles was $30 \mathrm{~nm}$. In $\mathrm{H}_{2} \mathrm{O}$, the micelles aggregated over time, increasing six-fold in size compared to day 0 (Fig. 2a). Less aggregation was observed in $10 \mathrm{mM}$ PBS (Fig. 2b), and no aggregation was observed for nanomicelles in PBS-containing physiological $\mathrm{NaCl}$ concentrations (150 mM, Fig. 2c). PBS (150 mM NaCl) was, therefore, selected for all further experiments.

\section{Sustained release profiling}

SAHA-loaded nanomicelles were analyzed for their capacity to sustain SAHA release over time (Fig. 3). SAHA was retained for a longer period of time when loaded in nanomicelles with only $36.53 \% \pm 3.43$ of drug released after $2 \mathrm{~h}$ and $85.68 \% \pm 2.48$ after $72 \mathrm{~h}$, compared to free SAHA where levels reached $51.55 \% \pm 1.56$ after $2 \mathrm{~h}$, $96.27 \% \pm 3.47$ after $72 \mathrm{~h}$. 


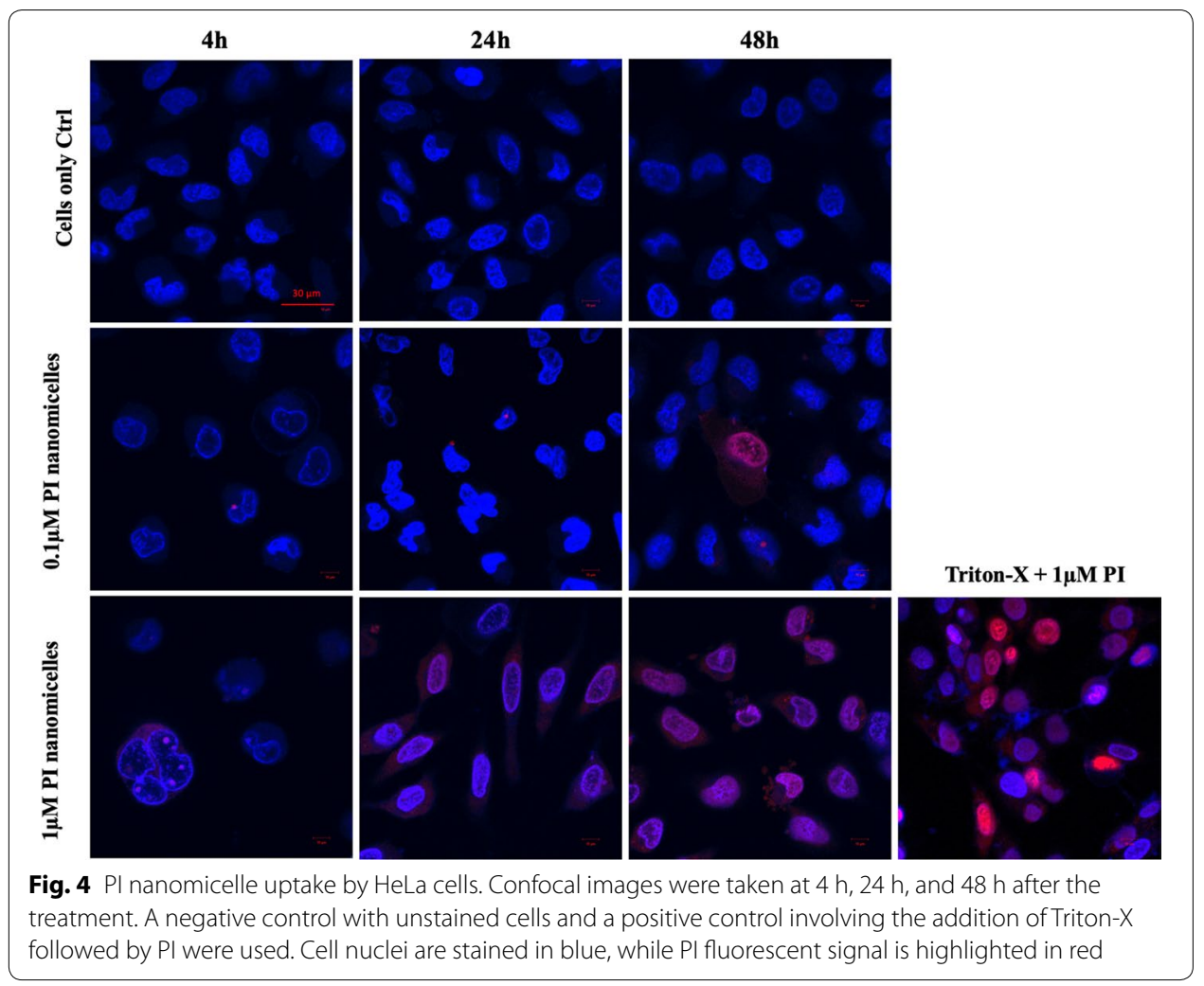

\section{Nanomicelles cellular uptake}

To understand the mechanisms of nanomicelle uptake, HeLa and MCF-7 cells were exposed to F127 nanomicelles loaded with the fluorescent dye propidium iodide (PI). Cellular uptake was assessed at $4 \mathrm{~h}, 24 \mathrm{~h}$ and $48 \mathrm{~h}$ time points. Nanomicelle uptake by HeLa cells was measured by confocal microscopy at two different concentrations, $0.1 \mu \mathrm{M}$ and $1 \mu \mathrm{M}$ (Fig. 4). Treatment with $0.1 \mu \mathrm{M}$ nanomicelles yielded a noticeable PI uptake after $48 \mathrm{~h}$, while the PI signal could already be visualized after $4 \mathrm{~h}$ following exposure to $1 \mu \mathrm{M}$ PI nanomicelles, where a clear co-localization signal was observed in the cell nuclei (blue, Fig. 4).

Treatment of MCF-7 cells with PI nanomicelles resulted in a different temporal cellular uptake pattern compared to HeLa cells (Fig. 5). Treatment with $0.1 \mu \mathrm{M}$ PI nanomicelles resulted in particle localization at the peri-nuclear zone after $24 \mathrm{~h}$, and localization within the nuclei after $48 \mathrm{~h}$, showing the intracellular transport of these particles to the nucleus can be accomplished using the delivery system. At higher treatment concentrations $(1 \mu \mathrm{M})$, particles reached the cell nuclei after only $4 \mathrm{~h}$ from the addition and yielded the highest signal after $48 \mathrm{~h}$.

\section{SAHA-loaded nanomicelles inhibit Hela cell and MCF-7 cell proliferation}

The ability of SAHA-loaded nanomicelles to inhibit cell proliferation in both Hela and MCF-7 cancer cell lines was assessed. HeLa and MCF7 cell lines were treated with $1 \mu \mathrm{M}$ and $5 \mu \mathrm{M}$ of free drug or SAHA-encapsulated nanoparticles for up to $72 \mathrm{~h}$. The $1 \mu \mathrm{M}$ 


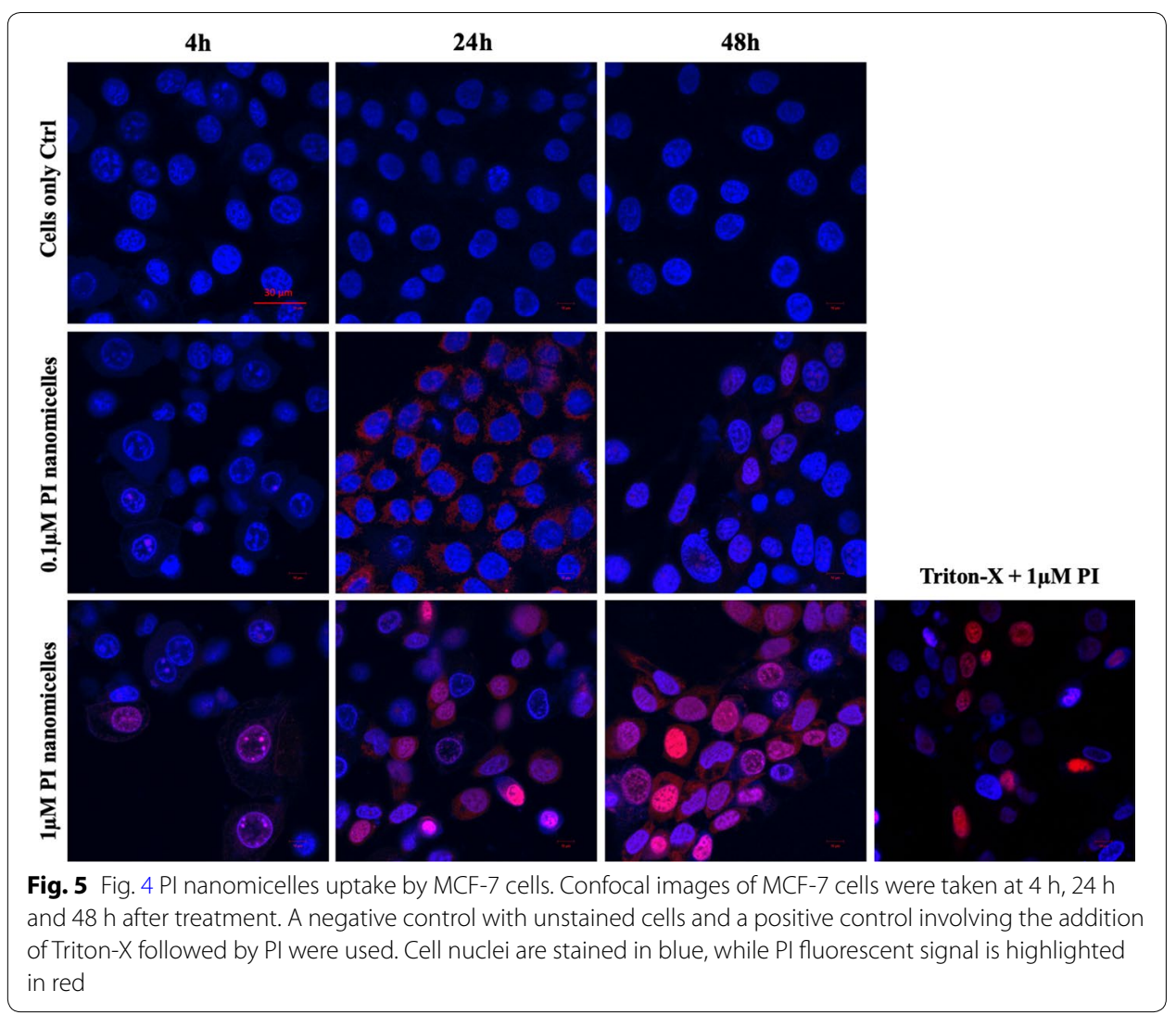

concentration of free and encapsulated drug displayed similar toxicities with both Hela and MCF7 cells after $24 \mathrm{~h}$ and $48 \mathrm{~h}$ (Fig. 6a, c), while the nanomicelles became significantly more effective than the free drug after $72 \mathrm{~h}$ on HeLa cells $(\mathrm{p}<0.05)$. Conversely, the $5 \mu \mathrm{M}$ concentration of SAHA-encapsulated nanomicelles proved to be more effective than the free drug after $48 \mathrm{~h}$ for both HeLa $(p<0.05$, Fig. $6 \mathrm{~b})$ and MCF7 $(p<0.01$, Fig. $6 \mathrm{~d}$ ). The same trends were maintained after $72 \mathrm{~h}$ of exposure to the treatment for both HeLa and MCF7 cells. These observations suggested that nanomicelle encapsulation of SAHA serves to enhance its cytotoxicity.

\section{Effect of SAHA-loaded nanomicelles on cell cycle and EMT}

To evaluate the effect of SAHA encapsulation on the expression of p21 and p53 (cell cycle markers) and E/N-cadherins (EMT markers), HeLa cells were treated with free and encapsulated drug for $24 \mathrm{~h}$ and $48 \mathrm{~h}$. Increasing concentrations of both free drug and SAHA-encapsulated nanomicelles led to a significant up-regulation of p21 $(p<0.05)$ and a down-regulation of p53 $(p<0.05)$ at both $24 \mathrm{~h}$ (Fig. $7 \mathrm{a}, \mathrm{b})$ and $48 \mathrm{~h}$ (Fig. $7 \mathrm{~d}-\mathrm{e}$ ). Moreover, SAHA-loaded nanomicelles were more effective than free SAHA $(p<0.05)$ in triggering alterations at the protein level (Figs. 7a, 4b), and this effect was corroborated by mRNA expression analysis of the same markers (Figs. 7c, 4f), with SAHA-loaded nanomicelles having a significantly greater effect on the expression of p21 and p53 mRNA $(p<0.01)$ than free drug. The effect of SAHA and SAHA-loaded nanomicelles on 

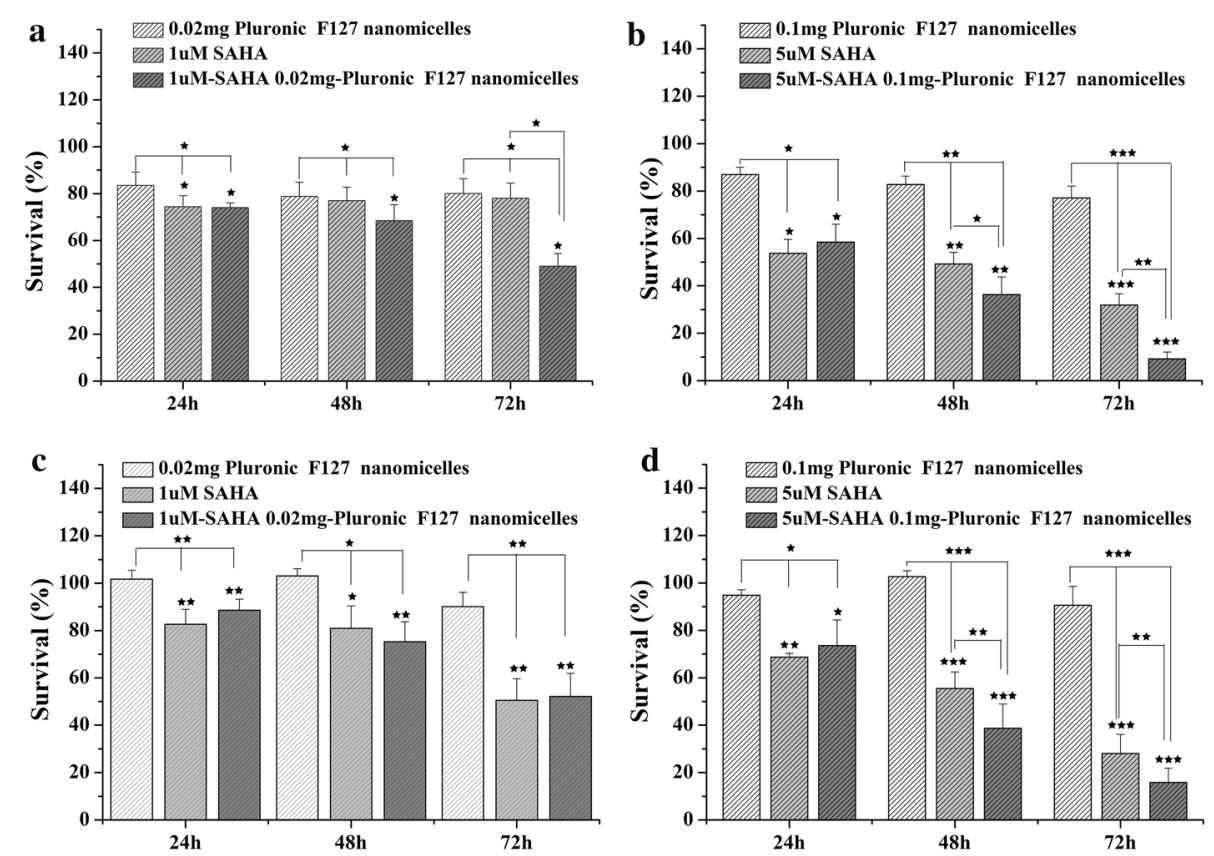

Fig. 6 Anti-proliferative effect of SAHA on Hela and MCF-7 cells. $\mathbf{a}$, $\mathbf{b}$ Effect of different drug concentrations on Hela cells at 24 h, 48 h, and 72 h. c, d effect of different drug concentrations on MCF-7 cells at 24 h, 48 h, and $72 \mathrm{~h}$. Survival rate was measured by MTT assay. The percentage of viable cells was determined as the ratio of treated cells to untreated controls. A one-way ANOVA was used to test for statistical significance $\left({ }^{*} p<0.05,{ }^{* *} p<0.01,{ }^{* * *} p<0.001\right)$

p21 and p53 protein expression appears concentration-dependent, with drug encapsulation potentiating the effect of SAHA in nanomicelles.

The effect of SAHA encapsulation in metastatic processes was undertaken by determining the expression patterns of E-cadherin and N-cadherin. After $24 \mathrm{~h}, \mathrm{SAHA}$ and SAHA-loaded nanomicelle treatement resulted in a significant up-regulation of E-cadherin protein in Hela cells $(p<0.05)$ (Fig. 7c). Similarly, the $48 \mathrm{~h}$ treatment with either SAHA and SAHA nanomicelles resulted in significantly increased E-cadherin expression $(p<0.05)$ (Fig. 7f). SAHA-encapsulated nanoparticles were more effective than free drug in increasing E-cadherin levels. However, neither SAHA nor SAHA-loaded nanomicelles had an effect on N-cadherin expression.

The same analysis was performed on MCF-7 cells, which displayed a similar response to Hela cells after $24 \mathrm{~h}$ treatment, with both SAHA and SAHA-loaded micelles significantly up-regulating p21 and down-regulating p53 protein (Fig. 8a) and mRNA expression levels (Fig. 8b). The same trend was seen after 48 h (Fig. 8d-e). Furthermore, SAHA-loaded nanomicelles exhibited a greater effect on protein expression on both targets compared to free SAHA $(p<0.05)$. Furthermore, gene expression analysis showed a significant increase in E-cadherin and decrease in N-cadherin after $24 \mathrm{~h}$ (Fig. 8c), which was maintained after $48 \mathrm{~h}$ for E-cadherin only (Fig. 8f). In general, SAHA-encapsulated nanoparticles were more effective in increasing the levels of E-cadherins than the free drug. 


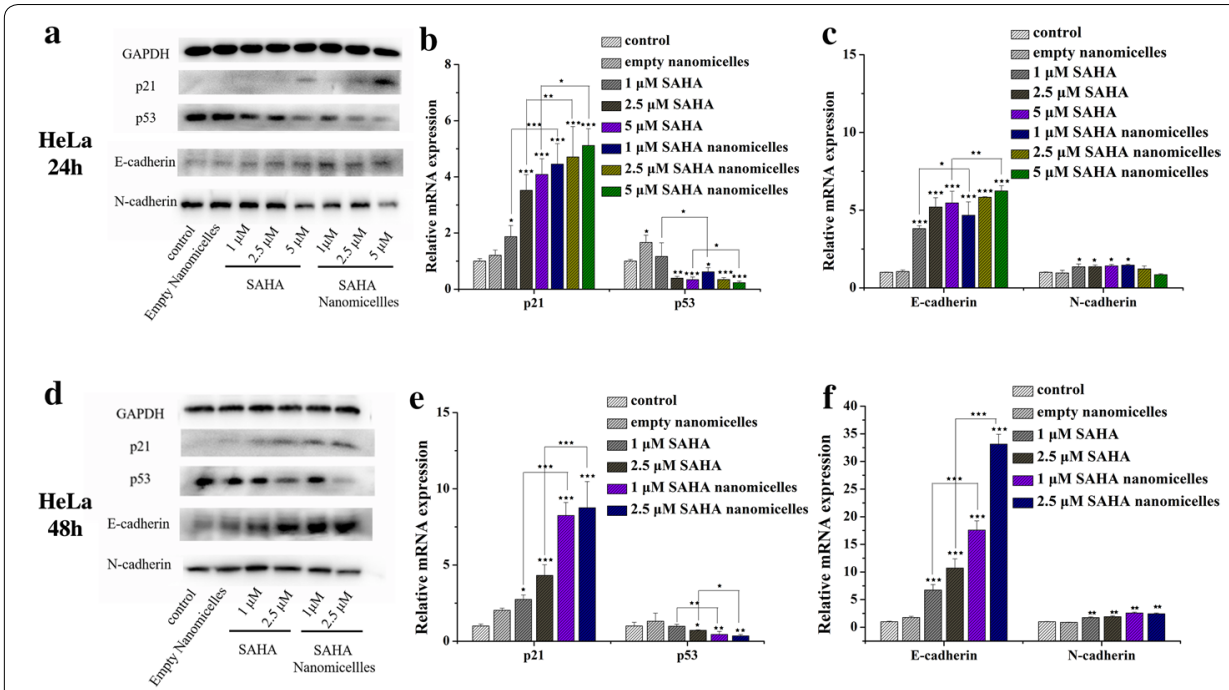

Fig. 7 Protein and mRNA expression of p21, p53, and E/N-cadherins in Hela cells after $24 \mathrm{~h}$ (top) or $48 \mathrm{~h}$ (bottom). Cells were analyzed by western blot and qPCR. $\mathbf{a}$, $\mathbf{d}$ Effect of SAHA and SAHA-loaded nanomicelles on the protein expression of the four markers in Hela cells at 24 and $48 \mathrm{~h}$. b. e mRNA analysis of p21 and p53 markers on Hela cells at 24 and 48 h. $\mathbf{c}, \mathbf{f}$ Effect of SAHA and SAHA-loaded nanomicelles on E and N-cadherin mRNA expression in Hela cells at both time points. Data were normalized to the level of GAPDH. Data were tested by T test for statistical significance $\left(n=3,{ }^{*} p<0.05,{ }^{* *} p<0.01,{ }^{* *} p<0.001\right)$

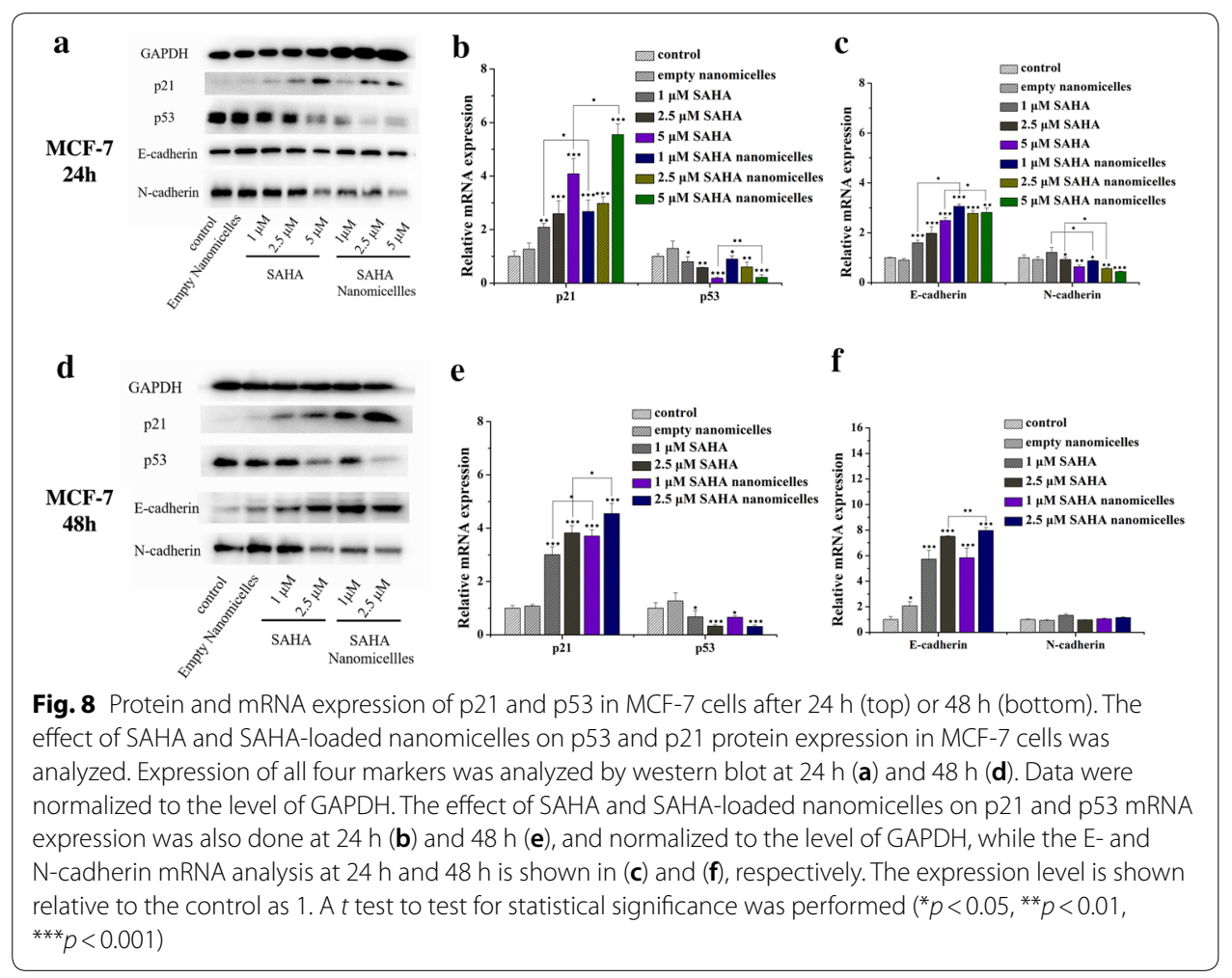




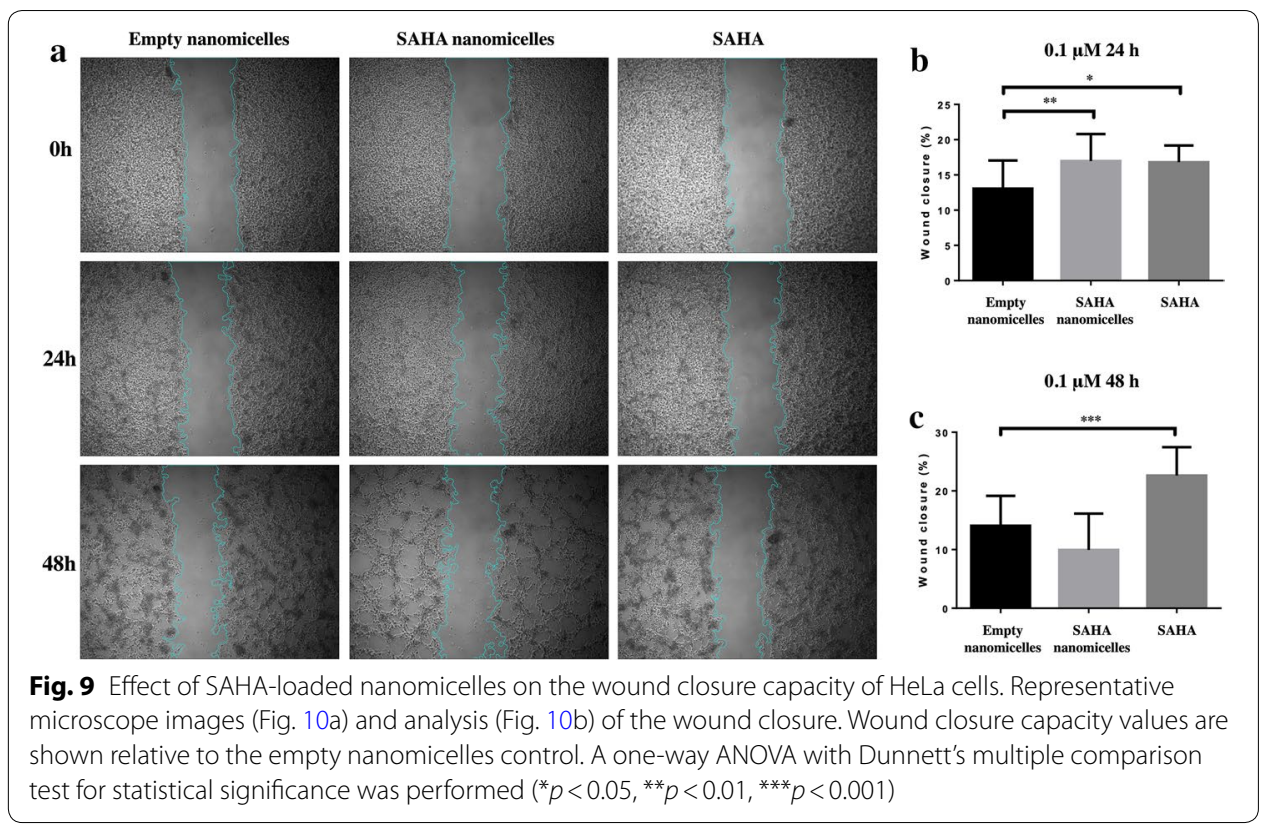

\section{Analysis of cell migration capacity following SAHA nanomicelle exposure}

$0.1 \mu \mathrm{M}$ SAHA nanomicelles were assessed for their ability to inhibit HeLa and MCF-7 cell growth and migration using a wound-healing assay. Following treatment for $24 \mathrm{~h}$ and $48 \mathrm{~h}$, a time-dependent effect of the treatment on HeLa cell division and inhibition of migration was observed (Fig. 9a). After $24 \mathrm{~h}$, both SAHA nanomicelles and SAHA were found to inhibit wound closure compared to empty nanomicelles $(p<0.01$ and $p<0.05$ respectively, Fig. 9b). After an extended $48 \mathrm{~h}$ treatment period, the negative effect of SAHA nanomicelles on wound closure was more marked than the free drug, which surprisingly was even less effective than the empty nanomicelle treatment ( $p<0.001$, Fig. 9c).

Similarly, when MCF-7 cells were exposed to $0.1 \mu \mathrm{M}$ SAHA nanomicelles, a clear decrease in wound-healing capacity was observed after $24 \mathrm{~h}$ (Fig. 10a, b). Moreover, this effect was more enhanced after $48 \mathrm{~h}$, where SAHA-nanomicelles yielded the most marked reduction in wound closure $(p<0.001)$ compared to SAHA only $(p<0.05$, Fig. 10c).

\section{Discussion}

Here, we have demonstrated that the histone deacetylase inhibitor SAHA can be effectively encapsulated in pluronic nanoparticles. We confirmed, by means of dynamic light scattering and AFM analysis, that the size and phenotype of nanomicelles did not change upon SAHA encapsulation.

As SAHA has been shown to cause harmful side-effects, analysis of the amount of encapsulated drug within the nanomicelles was undertaken, as encapsulation could be an effective route to reducing systemic toxicity. Reported side-effects include fatigue, GI related diarrhea, nausea, thrombocytopenia, and anorexia as observed in different types of cancers, including endometrial cancers and lymphomas (Takai et al. 2004; Duvic 2008). 
Drug release experiments showed that SAHA was progressively released from pluronic nanomicelles for up to $72 \mathrm{~h}$. These results were complemented by the analysis of the uptake of nanomicelles by breast and cervical cancer cell lines MCF-7 and HeLa, which showed a time-dependent nanomicelle uptake that was more enhanced in the MCF-7 cell line after $48 \mathrm{~h}$. This effect could be due to different intracellular uptake patterns of nano-encapsulated formulations by different cell types. Indeed, the majority of free drugs enter cells through a simple diffusion process, while most nanocarrier drugs enter cells through endocytosis (Kumari et al. 2016; Behzadi et al. 2017; Foroozandeh and Aziz 2018). These findings are in line with the previous reports that showed the efficient employment of pluronic F127 for the encapsulation and cellular uptake of compounds, such as curcumin (Wang et al. 2015; Vaidya et al. 2019), paclitaxel (Nie et al. 2011), and doxorubicin (Manaspon et al. 2012).

Experiments showed that nanomicelle-encapsulated SAHA was more effective than the free drug in causing cell death. This effect was most evident after $72 \mathrm{~h}$, suggesting a sustained release of SAHA over time. Encapsulation could, therefore, result in the use of less drug while still obtaining the required therapeutic effect, or in the more effective and tumor site specific delivery due to the inherent properties of nanostructures. A wound-healing assay further demonstrated the effectiveness of SAHA nanomicelles over longer time periods for HeLa and MCF-7 cells, with a slightly different effect observed with each cell line. Indeed, the fact that breast cancer cells were more susceptible to the effect of SAHA nanomicelles than cervical cancer cells might provide insights for future therapeutic approaches.

SAHA treatment caused significant changes in proteins involved in both cell cycle and cell phenotype. We demonstrated that SAHA-loaded nanomicelles were able to up-regulate $\mathrm{p} 21$ and down-regulate p53 expression, consistent with the previous studies on the action of free SAHA on tumor growth inhibition by regulating the expression of these genes (Davies et al. 2015; Ogata et al. 2017).

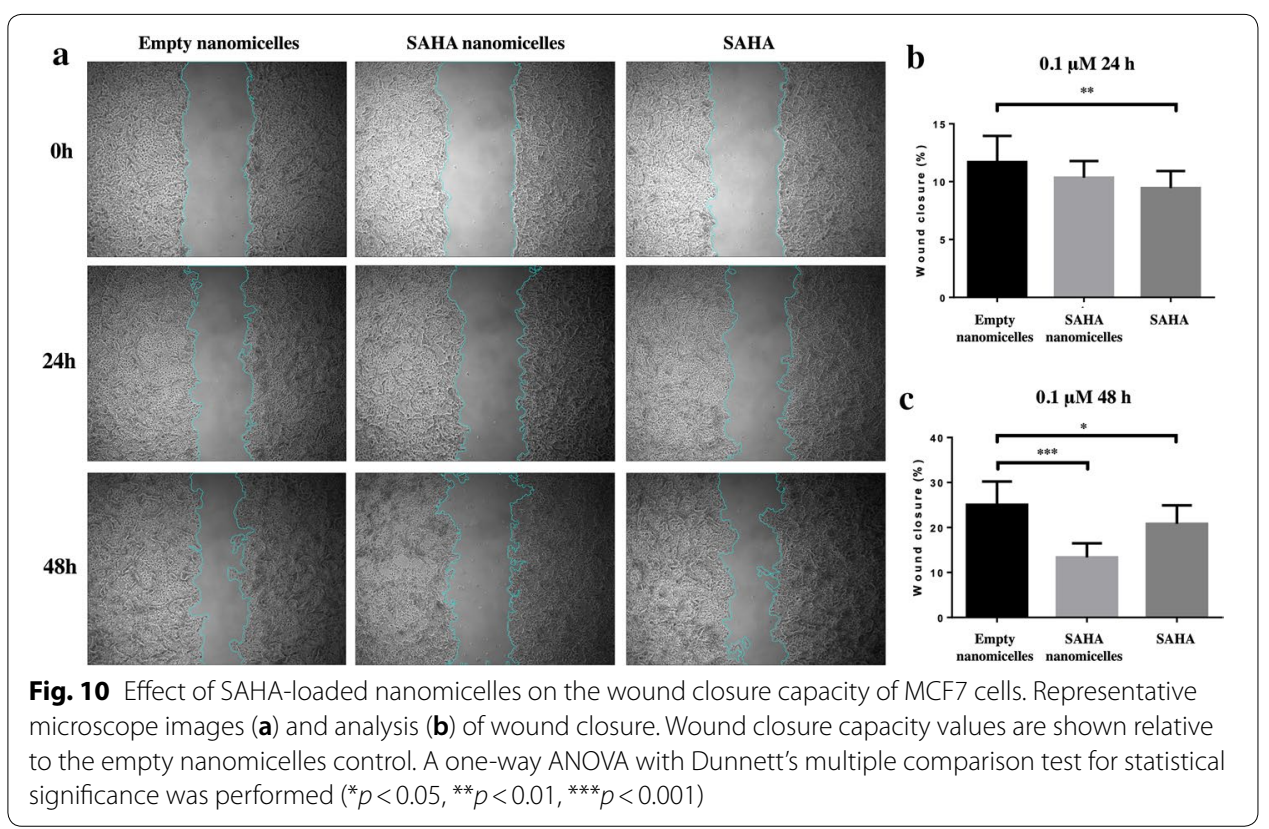


Detailed analysis of the effects of SAHA-loaded nanoparticles on EMT transition markers revealed a significant up-regulated E-cadherin expression, but with no affect $\mathrm{N}$-cadherin expression. This is consistent with previous studies, where HDAC inhibitors were shown to have only a slight effect on N-cadherin expression in HT-144 and A375 cells (Díaz-Núñez et al. 2016). Down-regulation or loss of E-cadherin expression affects cadherin-catenin complex formation and stability, which directly affects the metastatic process (Zhang et al. 2000; Guo et al. 2018). It has been suggested that SAHA may inhibit the formation of Snail and HDAC1/HDAC2 complexes by inhibiting the activity of HDAC1 and HDAC2, leading to the demethylation and transcriptional activation of the E-cadherin. In addition, SAHA may also up-regulate E-cadherin expression by altering its upstream targets (LEF-1 and Slug) (Nalls et al. 2011), but the specific mechanisms need to be further elucidated.

\title{
Conclusions
}

Encapsulation of SAHA into nanomicelles enhances the potency of this epigenetic drug in breast and cervical cancer cell models. Furthermore, this effective formulation will likely enhance drug delivery to tumor sites, and overcome current issues in delivering HDAC inhibitors to solid tumors, while also reducing side-effects associated with systemic delivery of the free drug. The EPR effect would enable these nanoparticles to escape via neo-vascularization at tumor sites, and subsequently, their physico-chemical characteristics would allow better penetration into solid tumors (Blanco et al. 2015; Zhang et al. 2019). Such parameters are likely to be specific to different cancer types, and indeed, we observed that the SAHA-loaded nanomicelles displayed different uptake rates, and directed intracellular trafficking in the two different cancer cell models tested here (Figs. 4, 5).

\begin{abstract}
Abbreviations
EMT: Epithelial-to-mesenchymal transition; SAHA: Suberoylanilide hydroxamic acid; CTCL: Cutaneous T-cell lymphoma; HDAC: Histone deacetylase; ROS: Reactive oxygen species; TSA: Trichostatin A; MDR: Multidrug resistance; EPR: Enhanced permeability and retention (effect); PEOx-PPOy-PEOz: Poly(oxyethylene)-block-poly (oxypropylene)-blockpoly(oxyethylene); CPZ: Chlorpromazine; DMSO: Dimethyl sulfoxide; DMEM: Dulbecco's Modified Eagle Medium; PBS: Phosphate buffer solution; PDI: Poly-dispersion index; HPLC: High-performance liquid chromatography; EE: Entrapment efficiency; DL: Drug loading (efficiency); CDK: Cyclin-dependent kinase; HDACi: Histone deacetylase inhibitors; AFM: Atomic force microscope; PI: Propidium iodide.
\end{abstract}

\section{Acknowledgements}

Not applicable.

\section{Authors' contributions}

Conceptualization and methodology: CL, RSC, and XW; formal analysis and data curation: SP and XW; validation and investigation: $X W, Y H, L H, S P, J G P, A G, K E$, and VF; writing —original draft preparation and writing-review and editing: SP, $X W, L F, D G, C L$, and RSC; approval of final manuscript: all authors. All authors read and approved the final manuscript.

\section{Funding}

This study received financial support from the Jiangsu Nature Science Foundation, BK20191188; the Life Sciences Research Network Wales project grant'Nanoparticle delivery of epigenetic modifiers: a targeted approach for Endometrial Cancer treatment'; the joint PhD program Swansea University and Houston Methodist; Welsh Government ERDF SMART Expertise 2014-2020 West Wales and the Valleys Grant RISE 2017/COL/001); National Natural Science Foundation of Youth Science Fund China (No. 22005237).

\section{Availability of data and materials}

The analyzed data sets generated during the present study are available from the corresponding author on reasonable request.

Ethics approval and consent to participate Not applicable. 


\section{Consent for publication}

Not applicable.

\section{Competing interests}

The authors declare that they have no competing interests.

\section{Author details}

${ }^{1}$ Institute of Life Science, Swansea University Medical School, Swansea University, Swansea SA2 8PP, UK. ${ }^{2}$ Department of Nanomedicine, Houston Methodist Research Institute, 6670 Bertner Ave., Houston, TX 77030, USA. ${ }^{3}$ School of Pharmacy, Health Science Center, Xi'an Jiaotong University, Xi'an, Shaanxi 710061, People's Republic of China. ${ }^{4}$ Xi'an Jiaotong University Suzhou Academy, Suzhou 215123, People's Republic of China. ${ }^{5}$ Ankang City Center Hospital, Ankang, Shaanxi 725000, People's Republic of China.

Received: 28 July 2020 Accepted: 15 November 2020

Published online: 25 November 2020

\section{References}

Audia JE, Campbell RM. Histone modifications and cancer. Cold Spring Harb Perspect Biol. 2016. https://doi.org/10.1101/ cshperspect.a019521.

Behzadi S, Serpooshan V, Tao W, et al. Cellular uptake of nanoparticles: journey inside the cell. Chem Soc Rev. 2017:46(14):4218-44.

Biswas S, Vaze OS, Movassaghian STV. Polymeric micelles for the delivery of poorly soluble drugs. New Jersey: Wiley; 2013.

Blanco E, Shen H, Ferrari M. Principles of nanoparticle design for overcoming biological barriers to drug delivery. Nat Biotechnol. 2015;33:941-51. https://doi.org/10.1038/nbt.3330.

Bravo-Cordero JJ, Hodgson L, Condeelis J. Directed cell invasion and migration during metastasis. Curr Opin Cell Biol. 2012;24(2):277-83.

Chung S, Yao J, Suyama K, et al. N-cadherin regulates mammary tumor cell migration through Akt3 suppression. Oncogene. 2013. https://doi.org/10.1038/onc.2012.65.

Davies C, Hogarth LA, Mackenzie KL, et al. P21WAF1 modulates drug-induced apoptosis and cell cycle arrest in B-cell precursor acute lymphoblastic leukemia. Cell Cycle. 2015. https://doi.org/10.1080/15384101.2015.1100774.

de Mello JC, Moraes VW, Watashi CM, et al. Enhancement of chlorpromazine antitumor activity by Pluronics F127/L81 nanostructured system against human multidrug resistant leukemia. Pharmacol Res. 2016;111:102-12. https://doi. org/10.1016/j.phrs.2016.05.032.

Díaz-Núñez M, Díez-Torre A, De Wever O, et al. Histone deacetylase inhibitors induce invasion of human melanoma cells in vitro via differential regulation of $\mathrm{N}$-cadherin expression and RhoA activity. BMC Cancer. 2016. https://doi. org/10.1186/s12885-016-2693-3.

Dupont C, Armant DR, Brenner CA. Epigenetics: definition, mechanisms and clinical perspective. Semin Reprod Med. 2009;27:351-7.

Duvic M. Histone deacetylase inhibitors: SAHA (Vorinostat). A treatment option for advanced cutaneous T-cell lymphoma. Haematol Meet Rep. 2008;2:39-43.

El-Say KM, El-Sawy HS. Polymeric nanoparticles: promising platform for drug delivery. Int J Pharm. 2017;528:675-91.

Fang J, Nakamura H, Maeda H. The EPR effect: Unique features of tumor blood vessels for drug delivery, factors involved, and limitations and augmentation of the effect. Adv Drug Deliv Rev. 2011:63(3):136-51.

Fardi M, Solali S, Farshdousti Hagh M. Epigenetic mechanisms as a new approach in cancer treatment: an updated review. Genes Dis. 2018;5(4):304-11.

Farrugia M, Morgan SP, Alexander C, Mather ML. Ultrasonic monitoring of drug loaded Pluronic F127 micellular hydrogel phase behaviour. Mater Sci Eng C. 2014. https://doi.org/10.1016/j.msec.2013.09.018.

Foroozandeh P, Aziz AA. Insight into cellular uptake and intracellular trafficking of nanoparticles. Nanoscale Res Lett. 2018;13(1):339.

Friedl P, Locker J, Sahai E, Segall JE. Classifying collective cancer cell invasion. Nat Cell Biol. 2012;14(8):777-83.

Haberland M, Montgomery RL, Olson EN. The many roles of histone deacetylases in development and physiology: implications for disease and therapy. Nat Rev Genet. 2009;10(1):32-42.

Guo M, Mu Y, Yu D, et al. Comparison of the expression of TGF- $\beta 1$, E-cadherin, N-cadherin, TP53, RB1CC1 and HIF-1a in oral squamous cell carcinoma and lymph node metastases of humans and mice. Oncol Lett. 2018. https://doi. org/10.3892/ol.2017.7456.

Kawamata N, Chen J, Koeffler HP. Suberoylanilide hydroxamic acid (SAHA; vorinostat) suppresses translation of cyclin D1 in mantle cell lymphoma cells. Blood. 2007. https://doi.org/10.1182/blood-2005-11-026344.

Kohn $\mathrm{P}$, Huettner $\mathrm{S}$, Komber $\mathrm{H}$, et al. The use of the PeakForce ${ }^{T M}$ quantitative nanomechanical mapping AFM-based method for high-resolution Young's modulus measurement of polymers. Macromolecules. 2018;22:12.

Konsoula R, Jung M. In vitro plasma stability, permeability and solubility of mercaptoacetamide histone deacetylase inhibitors. Int J Pharm. 2008. https://doi.org/10.1016/j.jpharm.2008.05.001.

Kumari P, Swami MO, Nadipalli SK, et al. Curcumin delivery by poly(lactide)-based co-polymeric micelles: an in vitro anticancer study. Pharm Res. 2016;33:826-41. https://doi.org/10.1007/s11095-015-1830-z.

Kwak TW, Kim DH, II JY, Kang DH. Antitumor activity of vorinostat-incorporated nanoparticles against human cholangiocarcinoma cells. J Nanobiotechnol. 2015. https://doi.org/10.1186/s12951-015-0122-4.

Landry JJM, PyI PT, Rausch T, et al. The genomic and transcriptomic landscape of a hela cell line. G3 Genes Genomes Genet. 2013:3:1213-24. https://doi.org/10.1534/g3.113.005777.

Lee MK. Liposomes for enhanced bioavailability of water-insoluble drugs: in vivo evidence and recent approaches. Pharmaceutics. 2020;12:264. 
Manaspon C, Viravaidya-Pasuwat K, Pimpha N. Preparation of folate-conjugated pluronic F127/chitosan coreshell nanoparticles encapsulating doxorubicin for breast cancer treatment. J Nanomater. 2012. https://doi. org/10.1155/2012/593878

Nalls D, Tang SN, Rodova M, et al. Targeting epigenetic regulation of mir-34a for treatment of pancreatic cancer by inhibition of pancreatic cancer stem cells. PLoS ONE. 2011. https://doi.org/10.1371/journal.pone.0024099.

Nie S, Hsiao WW, Pan W, Yang Z. Thermoreversible pluronic ${ }^{\circledR}$ F127-based hydrogel containing liposomes for the controlled delivery of paclitaxel: In vitro drug release, cell cytotoxicity, and uptake studies. Int J Nanomedicine. 2011;6:151-66. https://doi.org/10.2147/IJN.S15057.

Ogata T, Nakamura M, Sang M, et al. Depletion of runt-related transcription factor 2 (RUNX2) enhances SAHA sensitivity of p53-mutated pancreatic cancer cells through the regulation of mutant p53 and TAp63. PLoS ONE. 2017. https:// doi.org/10.1371/journal.pone.0179884

Prestegui-Martel B, Bermúdez-Lugo JA, Chávez-Blanco A, et al. N-(2-hydroxyphenyl)-2-propylpentanamide, a valproic acid aryl derivative designed in silico with improved anti-proliferative activity in HeLa, rhabdomyosarcoma and breast cancer cells. J Enzyme Inhib Med Chem. 2016;31:140-9. https://doi.org/10.1080/14756366.2016.1210138.

Qi SS, Sun JH, Yu HH, Yu SQ. Co-delivery nanoparticles of anti-cancer drugs for improving chemotherapy efficacy. Drug Deliv. 2017;24:1909-26.

Russo A, Pellosi DS, PagliaraV, et al. Biotin-targeted Pluronic ${ }^{\circledR}$ P123/F127 mixed micelles delivering niclosamide: a repositioning strategy to treat drug-resistant lung cancer cells. Int J Pharm. 2016;511:127-39. https://doi.org/10.1016/j. ijpharm.2016.06.118.

Shi XY, Ding W, Li TQ, et al. Histone deacetylase (HDAC) inhibitor, suberoylanilide hydroxamic acid (SAHA), induces apoptosis in prostate cancer cell Lines via the Akt/FOXO3a signaling pathway. Med Sci Monit. 2017;23:5793-802. https:// doi.org/10.12659/MSM.904597.

Siegel RL, Miller KD, Jemal A. Cancer statistics, 2020. CA Cancer J Clin. 2020. https://doi.org/10.3322/caac.21590.

Suarez-Arnedo A, Figueroa FT, Clavijo C, et al. An image J plugin for the high throughput image analysis of in vitro scratch wound healing assays. PLOS ONE. 2020. https://doi.org/10.1371/journal.pone.0232565.

Takai N, Desmond JC, Kumagai T, et al. Histone deacetylase inhibitors have a profound antigrowth activity in endometrial cancer cells histone deacetylase inhibitors have a profound antigrowth activity in endometrial cancer cells. Clin Cancer Res. 2004;10:1141-9.

Tran TH, Choi JY, Ramasamy T, et al. Hyaluronic acid-coated solid lipid nanoparticles for targeted delivery of vorinostat to CD44 overexpressing cancer cells. Carbohydr Polym. 2014. https://doi.org/10.1016/j.carbpol.2014.08.026.

Tsutsui Y, Tomizawa K, Nagita M, et al. Development of bionanocapsules targeting brain tumors. J Control Release. 2007. https://doi.org/10.1016/j.jconrel.2007.06.019.

Vaidya FU, Sharma R, Shaikh S, et al. Pluronic micelles encapsulated curcumin manifests apoptotic cell death and inhibits pro-inflammatory cytokines in human breast adenocarcinoma cells. Cancer Rep. 2019;2:e1133. https://doi. org/10.1002/cnr2.1133.

Ververis K, Hiong A, Karagiannis TC, Licciardi PV. Histone deacetylase inhibitors (HDACIS): multitargeted anticancer agents. Biol Targets Ther. 2013;7:47-60.

Wang J, Ma W, Tu P. The mechanism of self-assembled mixed micelles in improving curcumin oral absorption: In vitro and in vivo. Colloids Surfaces B Biointerfaces. 2015;133:108-19. https://doi.org/10.1016/j.colsurfb.2015.05.056.

Xu WS, Parmigiani RB, Marks PA. Histone deacetylase inhibitors: molecular mechanisms of action. Oncogene. 2007;3(2):166-79.

Zeng Z, Peng Z, Chen L, Chen Y. Facile fabrication of thermally responsive Pluronic F127-based nanocapsules for controlled release of doxorubicin hydrochloride. Colloid Polym Sci. 2014. https://doi.org/10.1007/s00396-014-3183-2.

Zhang J, Zhong Q. Histone deacetylase inhibitors and cell death. Cell. Mol. Life Sci. 2014;71 (20):3885-901.

Zhang ZY, Wu YQ, Zhang WG, et al. The expression of E-cadherin-catenin complex in adenoid cystic carcinoma of salivary glands. Chin J Dent Res. 2000;3:36-9.

Zhang D, Tao L, Zhao H, et al. A functional drug delivery platform for targeting and imaging cancer cells based on Pluronic F127. J Biomater Sci Polym Ed. 2015. https://doi.org/10.1080/09205063.2015.1030136.

Zhang YR, Lin R, Li HJ, et al. Strategies to improve tumor penetration of nanomedicines through nanoparticle design. Wiley Interdiscip. Rev. Nanomedicine Nanobiotechnology. 2019;11(1):e1519.

Zhou X, Liu Z, Wang H, et al. SAHA (vorinostat) facilitates functional polymer-based gene transfection via upregulation of ROS and synergizes with TRAIL gene delivery for cancer therapy. J Drug Target. 2019;27:306-14. https://doi. org/10.1080/1061186X.2018.1519028.

Zhu Y, Liao L. Applications of nanoparticles for anticancer drug delivery: a review. J Nanosci Nanotechnol. 2015:15:4753-73.

Zhu P, Zhao N, Sheng D, et al. Inhibition of growth and metastasis of colon cancer by delivering 5-fluorouracil-loaded Pluronic P85 copolymer micelles. Sci Rep. 2016. https://doi.org/10.1038/srep20896.

\section{Publisher's Note}

Springer Nature remains neutral with regard to jurisdictional claims in published maps and institutional affiliations. 